\title{
Clinical data and hearing of individuals with Alport syndrome
}

\section{Fatima Regina Abreu Alves, ${ }^{1}$ Fernando de Andrade Quintanilba Ribeiro ${ }^{2}$}

Keywords: hereditary, genetics, nephritis, hearing loss.

\section{Summary}

\begin{abstract}
A Iport Syndrome (AS) is a hereditary disease, characterized by nephropathy, often times with sensorineural hearing loss and ocular defects. Aim: to analyze the clinical and hearing information from individuals with AS, more specifically the correlation between renal disorder and hearing loss (HL). Study design: clinical prospective with cross-sectional cohort. Materials and Methods: 37 individuals underwent otorhinolaryngological evaluation and were submitted to audiologic tests. For HL statistical analysis we considered only the results from the pure tone audiometries. Results: of the 28 individuals with clinical alterations, we found $46.4 \%$ of DLX and $53.6 \%$ of AD. HL happened to $46.1 \%$ of the individuals evaluated. 12 patients presented HL in the audiometric test: $11.5 \%$ mild and $34.6 \%$ moderate. Comparing the normal relatives with those with renal disorder; all that had HL also had renal disorder. In 30.8\% the curve shape was mild descending in the high frequencies and in $11.5 \%$ it was flat. Conclusions: The inheritance pattern distribution does not match literature descriptions. HL is a frequent extra-renal finding. There is an association between renal involvement and HL $(p=0.009)$. The most frequent curve shapes: mild descending in the high frequencies and flat. There was no association between HL and age. There is no correlation between the HL and gender in this group.
\end{abstract}

\footnotetext{
${ }^{1} \mathrm{PhD}$ student in Otorhinolaryngology - Master in ENT - FCMSC-SP. Preceptor - ENT Ward - HSPM - SP.

${ }^{2} \mathrm{PhD}$ in Otorhinolaryngology - UNIFESP - EPM. Head Physician - Santa Casa de Misericórdia de São Paulo. Study developed at the Department of Otorhinolaryngology - Santa Casa de São Paulo.

Send correspondence to: Dra. Fátima Regina Abreu Alves - Av. Moema 801 São Paulo SP 04077-023. Tel: (0xx11) 5052-4344 - Fax: (0xx11)5052-0093 - E-mail: ffraa@terra.com.br "Scholarship Holder - CNPq - Brazil".

This paper was submitted to the RBORL-SGP (Publishing Manager System) on 17 June 2007. Code 4613. The article was accepted on 22 September 2007.
} 


\section{INTRODUCTION}

Alport Syndrome (AS) is a hereditary disorder characterized by hematuria, which usually leads to renal failure. It can be followed by extra-renal manifestations. Therefore, often times, kidney disease is associated with sensorineural hearing loss (SNHL) and ocular effects. ${ }^{1}$ The dominant type is X related (DLX), happening in $85 \%$ of the cases, the autosomal recessive type (AR) happens in 10 to $15 \%$ of the cases, and the dominant autosomal (DA) type is rare. ${ }^{2}$ Improvements in molecular diagnosis may show that the DA type is not so uncommon. ${ }^{3}$ Mutations in the COL4A5 gene greatly, or possibly thoroughly, explain the X-related AS.4 In order to understand AS, it is necessary to understand the type IV collagen structure (Figure 1).5 Type IV collagen is the main component of basal membranes. a3, a4 and a5 (IV) chains selectively express the basal membranes of some tissues, such as the kidney (glomerular basal membranes), the cochlea and the eye. Mutations present in AS cause defects on the a3, a4 and a5 (IV) chains. Such defects result in an intertwining and incorrect assemblage of monomers, which will be promptly degraded. The following signs are observed in the clinical settings of AS. Hematuria is a cardinal sign and it is seen in the first year of life. Proteinuria reflects a specific glomerular involvement, and it is absent in the first years of life. Renal failure ensues progressively. SNHL is of variable intensity, bilateral, symmetrical and progressive. The DLX type happens more frequently to men when compared to women. Ocular alterations: anterior lens cone (happens

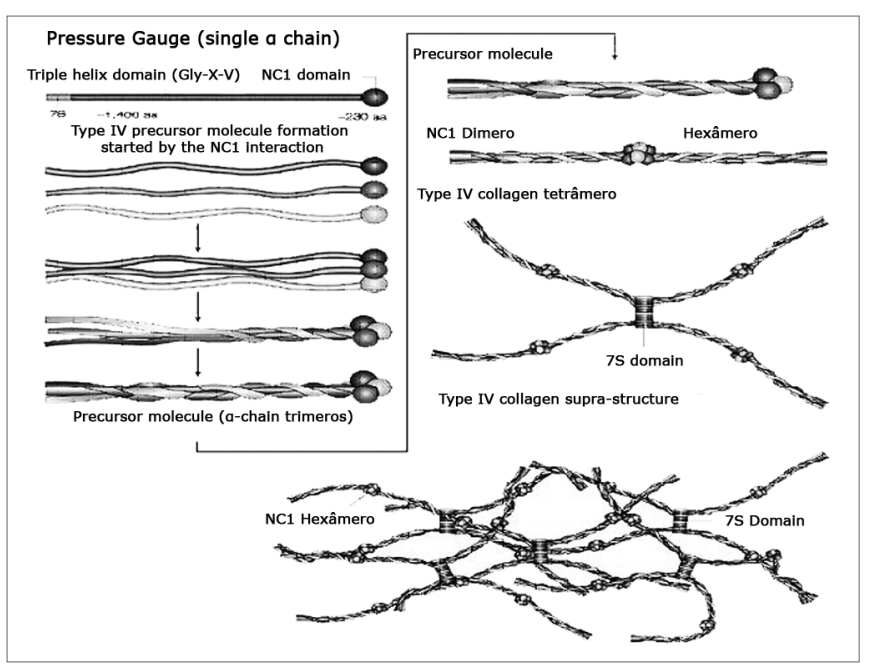

Figure 1. Type IV collagen structure. - Chains $x 3, \times 4$ and $x 5$ (IV) are expressed on the basal membranes of kidneys, cochlea and eye. The mutations present in AS cause defects in these chains. The damage done to type IV collagen, caused by mutation, breaks its epithelial linkage function and causes organ damage. Modified from Kalluri,2003. Gly=glycin; $\mathrm{X}=$ proline; $\mathrm{Y}=$ hydroxyproline; $\mathrm{NC1}=$ non-collagenous carboxy-terminal globular portion; $7 \mathrm{~S}=$ amino-terminal domain; aa $=$ amino acids. in 10 to 30\% of the cases and it is pathognomonic of AS), ocular spots, cataract, nystagmus and myopia. Hematuria happens early on, SNHL evolves during the school years, and the final stage of renal failure and ocular alterations happens at the end of adolescence. ${ }^{6}$

\section{OBJECTIVES}

The goal is to analyze clinical and hearing data from individuals with Alport Syndrome, with emphasis in the correlation between renal alteration and hearing loss.

\section{MATERIALS AND METHODS}

This study and the Free Consent Form were approved by the Institution's Ethics in Research Committee (Project \# 118/05). This is a cross-sectional cohort clinical prospective study.

We assessed eight families and drew the respective genetic map, with information of at least one more generation. Clinical and audiologic data of the index cases (proband: members from which a family with genetic disorders is initially evaluated) referred were collected, and the family members who agreed to participate were evaluated. All the families matched at least two strict diagnostic criteria.

Thirty-seven individuals from these families agreed to take part in the study and carried out an assessment made of: detailed clinical and family history, complete otorhinolaryngological physical exam, assessing prior lab exam results (blood tests, urine, ultrasound and renal biopsy). Families 2, 5, 6 and 8 had individuals who underwent renal biopsy with histological alterations matching those found in individuals with Alport Syndrome. Patients did not have prior history of noise exposure nor of using ototoxic agents. Families 1, 4 and 5 had individuals with ocular alterations. We did not see any patient with anterior lens cone.

Audiological tests were carried out following the same standardization in index cases and in other family members who agreed to take part in the project. Children below three years of age who did not respond properly to the tests or could not be conditioned, for statistical purposes, were considered as not having gone through audiometric tests.

Results were classified, considering the mean value at 500, 1.000, 2.000 and $4.000 \mathrm{~Hz}$, in the worst ear in: mild (21 - $40 \mathrm{~dB} \mathrm{HL})$; moderate ( 41 - $60 \mathrm{~dB} \mathrm{HL})$; moderately severe (61 - $80 \mathrm{~dB} \mathrm{HL})$; severe ( 81 - $100 \mathrm{~dB} \mathrm{HL})$; profound (> $100 \mathrm{~dB} \mathrm{HL})$ and not tested. ${ }^{7}$

A $15 \mathrm{~dB}$ difference between the ears in at least two frequencies or a $10 \mathrm{~dB}$ difference in four frequencies defines an asymmetrical hearing loss, and the symmetrical hearing loss has the same configuration and difference < $15 \mathrm{~dB}$ in the same frequencies between the ears. ${ }^{7}$ 
Audiometric curves were classified according to what was described on Table 1 , in flat, sudden drop in the high frequencies, mild drop in the high frequencies, specific (U type or ascending) and residual. ${ }^{8}$

The genetic maps of the eight families were crafted from the data collected and with the results from the audiologic tests, separating the ones who took part in the study (in red) from those who only provide information.

Using the EpiInfo software, version 3.2, the following statistical tests were applied: chi-squared (c2) and Fisher Exact Test. We considered a 95\% confidence interval in our statistical comparisons.

\section{RESULTS}

1 - Genetic maps

Using standard symbols, the information obtained about the family history of the probands evaluated were graphically shown in the following genetic maps (Figures 2-9).

data

2 - Statistical analysis of the clinical and hearing

Thirty-seven members from the eight families went through the evaluation approved by the Ethics in Research Committee of the Institution (Project \# 118/05). The nine normal individuals were taken off the study.

Females prevailed in this group $(16 / 28 ; 57.1 \%)$, and males were less commonly found (12/28; 42.9\%).

Adults prevailed in this group of patients (12/28; $42.9 \%)$; pre-school and school aged children and teenagers together represent 50.0\% (14/28).

Inheritance patterns were obtained after we created and analyzed the inheritance patterns. In this sample we found $46.4 \%$ of DLX and $53.6 \%$ of DA.

Twelve patients had hearing alterations in their audiometric tests: $11.5 \%(3 / 26)$ with mild alteration and $34.6 \%(9 / 26)$ with moderate alteration. Infants (below two years of age) who could not undergo the pure tone audiometry were taken off the analysis. In relation to the patients with mild hearing alterations age range $(3 / 26)$ : one was of school age (11 years) and two were adults. Of the patients with moderate alteration (9/26) the age distribution is the following: one school aged child (eight years), two teenagers (14 and 17 years) and six adults. Hearing loss happened in $46.1 \%(12 / 26)$ of the individuals evaluated. Five patients were referred to hearing aid fitting during our study.

We analyzed family members without clinical problems and we compared them with those that had renal disorder. All of those who had hearing problems also had renal involvement. There is an association between renal involvement and hearing impairment $(\mathrm{p}=0.009)$. RD\%: $20.36-61.45 .52 \%(13 / 25)$ of the patients in any stage of the renal disease did not have alterations in their audiologic tests. 48\% (12/25) of the patients at any stage of the renal disease manifested mild or moderate hearing disorder. From this analysis we excluded those infants (2/37) who did not undergo pure tone audiometry and one individual (1/37) who had not undergone urine tests during the study.

13 patients had normal audiometric curves (50.0\%) and $30.8 \%$ have a mildly descending curve in the high frequencies (8/26). A flat curve happened in 11.5\% (3/26). The less frequent configurations were: sudden drop in high frequencies and $U$ type. Two infants were taken off the study.

In the group studied, although we observed 30.8\% (8/26) with symmetrical hearing loss when both ears are compared, 19.2\% (5/26) had asymmetrical hearing loss. Two infants were taken off the study.

We observed hearing alterations in the school-aged children, in the adolescents and in adults. We did not detect hearing changes in pre-school aged children. We took off the study those two infants who did not undergo pure tone audiometry. There was no statistically significant correlation between the hearing alteration and age among the patients studied.

In this group we observed $60.0 \%(6 / 10)$ of men with hearing disorder and 37.5\% (6/16) of women with hearing disorder. There were 10/16 (62.5\%) women without hearing disorder and 4/10 (40.0\%) of men with the same problem. Two did not undergo audiometry because their ages were not suitable for the test. Literature reports that hearing loss happens, more frequently, in men when compared to women.

\section{DISCUSSION}

In this study we had more women (57.1\%) being evaluated than men (42.9\%). In family 2 we noticed four males who died and in family 8 there were three members who died. This could also contribute to a lower participation of men in the study (Table 2).

Pre-school aged, school aged and adolescents make up 50.0\% (14/28) of the cases analyzed (Table 3). In the Brazilian population there is still a large number of children; however the population has aged in recent years, and this changed the age range distribution and the pyramid's shape. In the demographic census of 2000, adults prevailed and it was also seen in the group we studied (42.9\%).

The creation of inheritance patterns and discussing them with the genetic team has contributed to the analysis of the families (Figures 2 to 9). We observed intra and interfamily variability. The inheritance pattern analysis allowed us to suppose the occurrence of a new mutation in family 7 (II-2).

Proving that hearing disorder helps diagnose AS in the patients who had not undergone renal biopsy, making up a strict diagnostic criteria. Renal biopsy may be dubious 
Table 1. Audiometric curve configuration classification.

\begin{tabular}{ll}
\hline \multicolumn{1}{c}{ Curve configuration } & \multicolumn{1}{c}{ Definition } \\
\hline Flat & High, middle and low frequencies differ in less than $10 \mathrm{dBHL}$ \\
$\begin{array}{l}\text { Sudden drop in the high } \\
\text { frequencies }\end{array}$ & The mean difference at $4.000,6.000$ and 8.000 and the mean value at $500,1.000$ and $2.000 \mathrm{~Hz}$ is higher \\
Mild drop in the high & than $25 \mathrm{dBHL}$, or the difference between any octave of a frequency is higher than $25 \mathrm{dBHL}$ \\
Frequencies & The mean difference at $4.000,6.000$ and 8.000 and the mean value at $500,1.000$ and $2.000 \mathrm{~Hz}$ is betwe- \\
Residual & en 10 and $24 \mathrm{dBHL}$ \\
$U$ type & Remaining in the low frequencies \\
Ascending & Mid-range frequencies are worse than their high and low counterparts in $15 \mathrm{dBHL}$ or more \\
\hline
\end{tabular}

Source: West China University of Medical Sciences, China e Manchester University, England.

Table 2. Individuals broken down by gender.

\begin{tabular}{lccc}
\hline \multicolumn{1}{c}{ Gender } & Frequency & Percentage & \% Cumulative \\
\hline Males & 12 & $42.9 \%$ & $42.9 \%$ \\
Females & 16 & $57.1 \%$ & $100.0 \%$ \\
\hline Total & 28 & $100.0 \%$ & $100.0 \%$ \\
\hline
\end{tabular}

Table 3. Individuals broken down by age.

\begin{tabular}{lccc}
\hline \multicolumn{1}{c}{ Age range } & Frequency & Percentage & \% Cumulative \\
\hline Infant & 2 & $7.1 \%$ & $7.1 \%$ \\
Pre-school & 4 & $14.3 \%$ & $21.4 \%$ \\
School & 4 & $14.3 \%$ & $35.7 \%$ \\
Adolescent & 6 & $21.4 \%$ & $57.1 \%$ \\
Adult & 12 & $42.9 \%$ & $100.0 \%$ \\
\hline Total & 28 & $100.0 \%$ & $100.0 \%$ \\
\hline
\end{tabular}

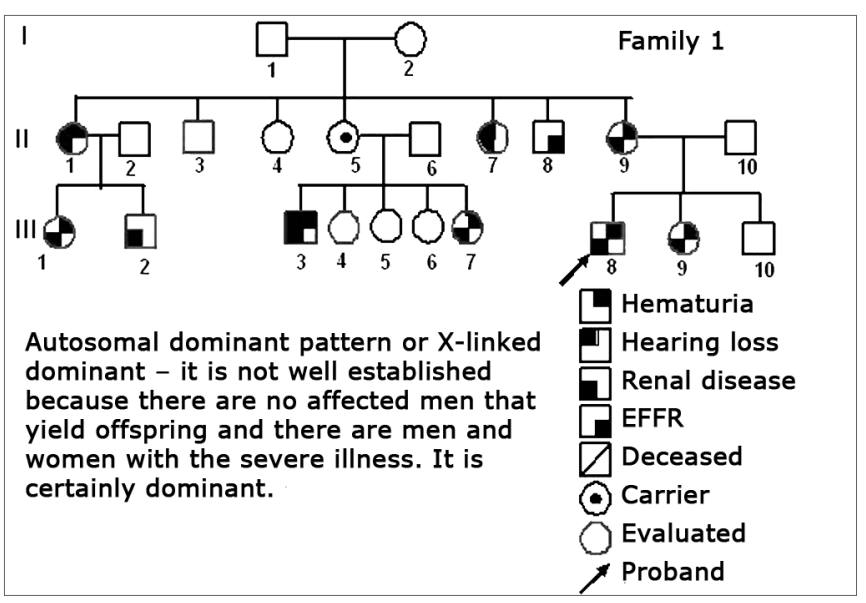

Figure 2. Family 1 Inheritance pattern - Probably autosomal dominant, with variable expression. Men and women are equally affected.

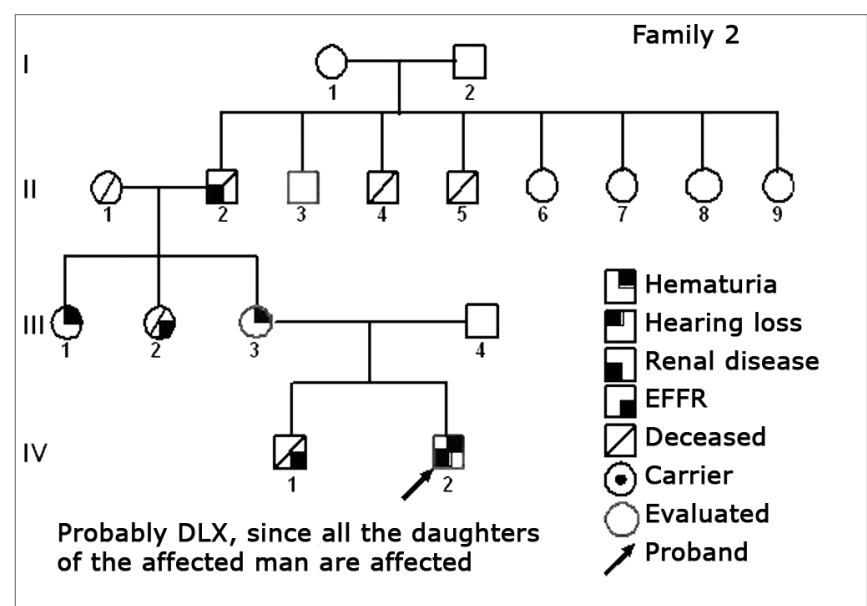

Figure 3. Family 2 Inheritance pattern - Probably DLX, because all daughters of the affected II-2 were affected.

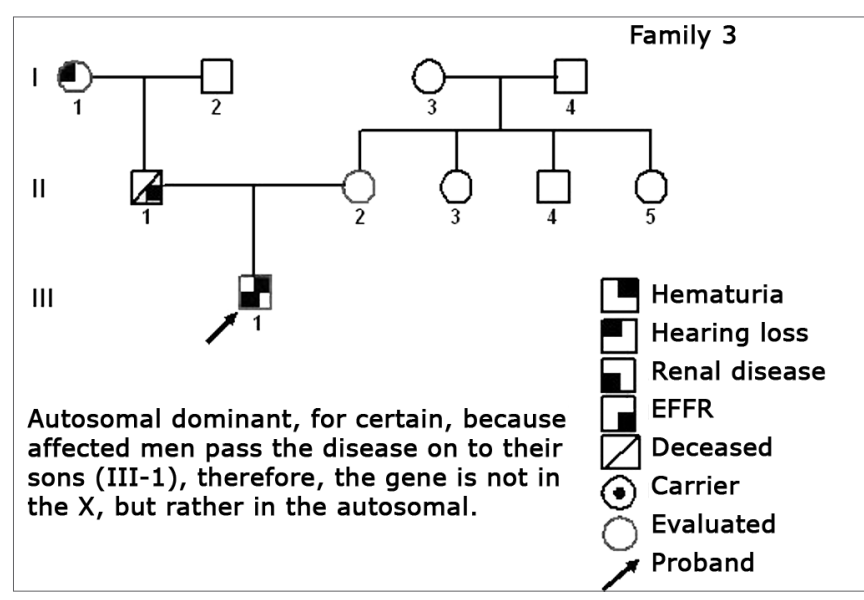

Figure 4. Family 3 Inheritance pattern - Autosomal dominant, because the affected man (II-1) passes on the disease for his son (III-1), therefore the gene is not in the $\mathrm{X}$, but rather in a chromosome. 


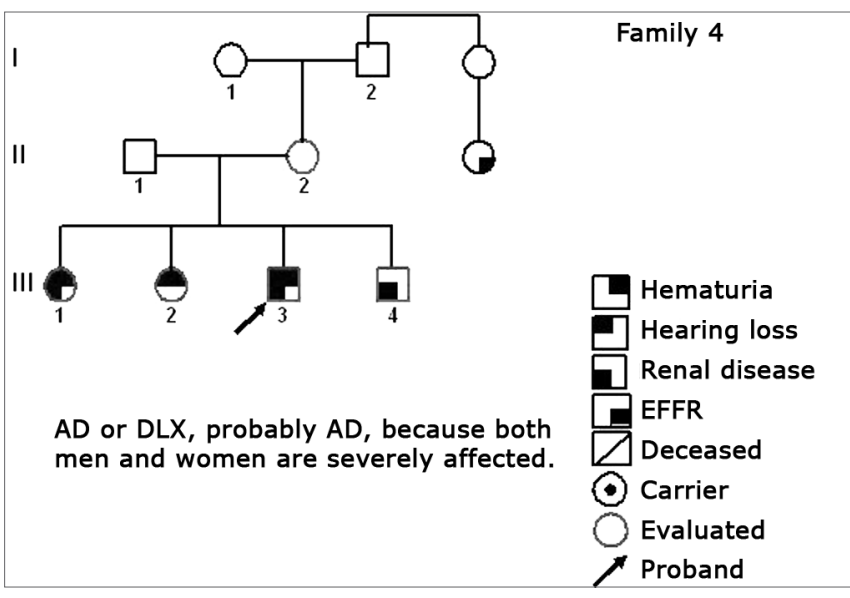

Figure 5. Family 4 Inheritance pattern - Probably AD. Cases III-1, III-3 and III-4 are very much diseased. DLX women have milder involvement than men.

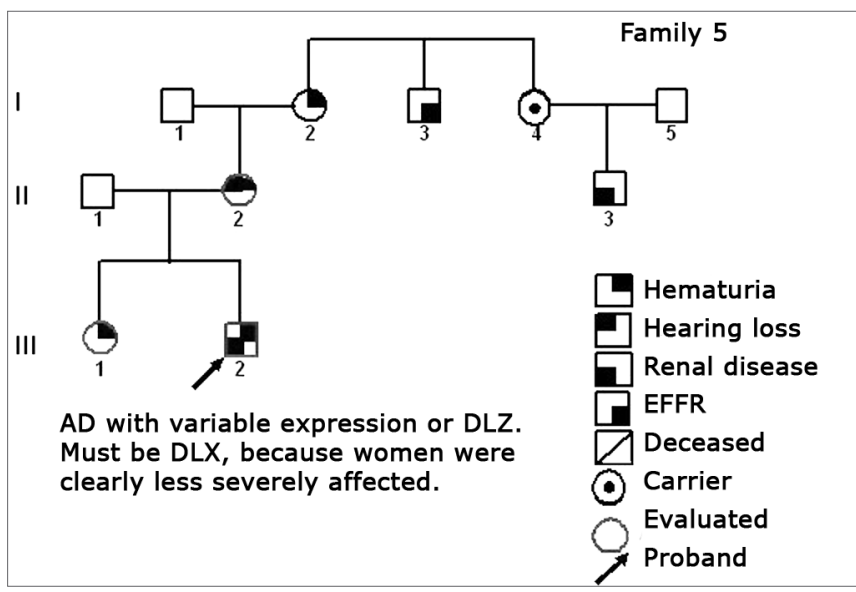

Figure 6. Family 5 Inheritance pattern - Probably DLX. The severity contrast between men and women matches this inheritance pattern.

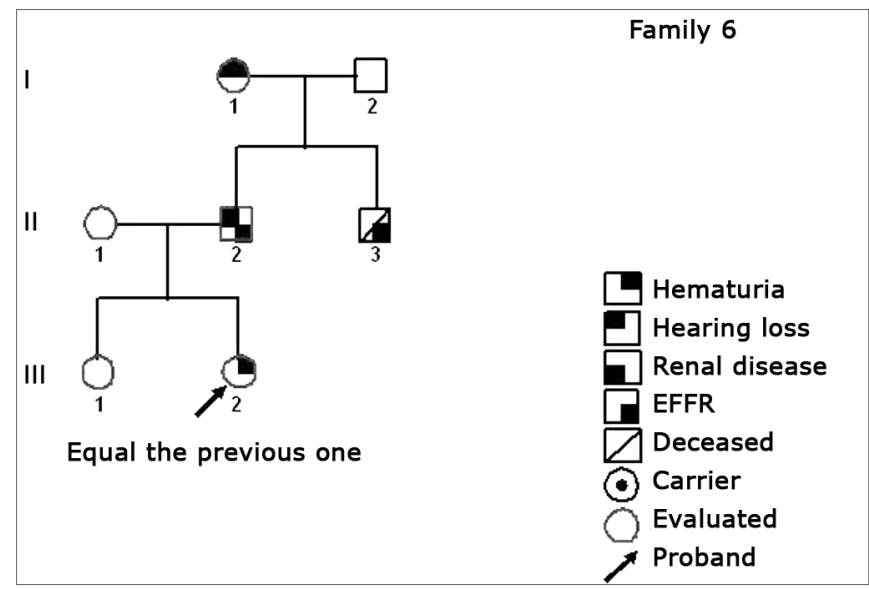

Figure 7. Family 6 Inheritance pattern - Probably DLX. The characteristic of a DLX inheritance pattern DLX, totally penetrating is that all the daughters and none of the men involved are affected.

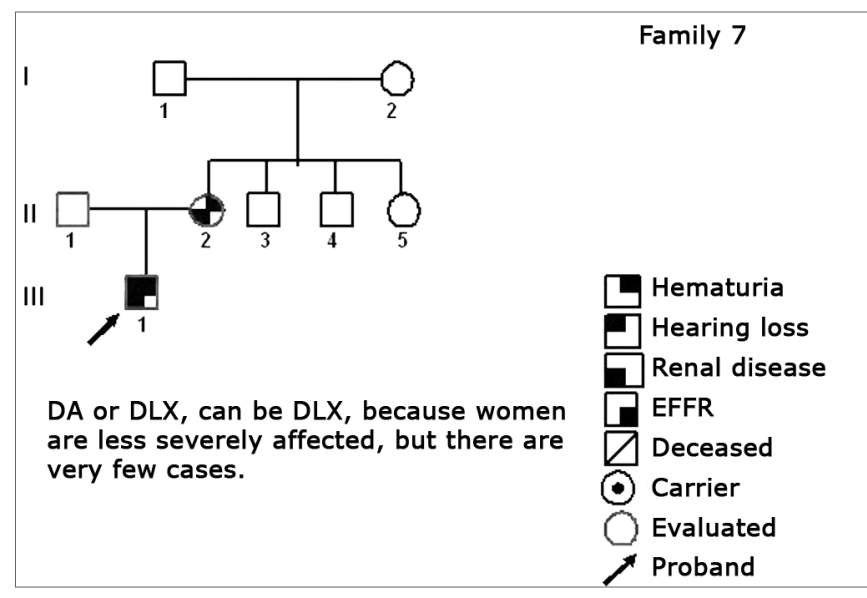

Figure 8. Family 7 Inheritance pattern - Probably DLX. Women are less affected; however there are fewer cases.

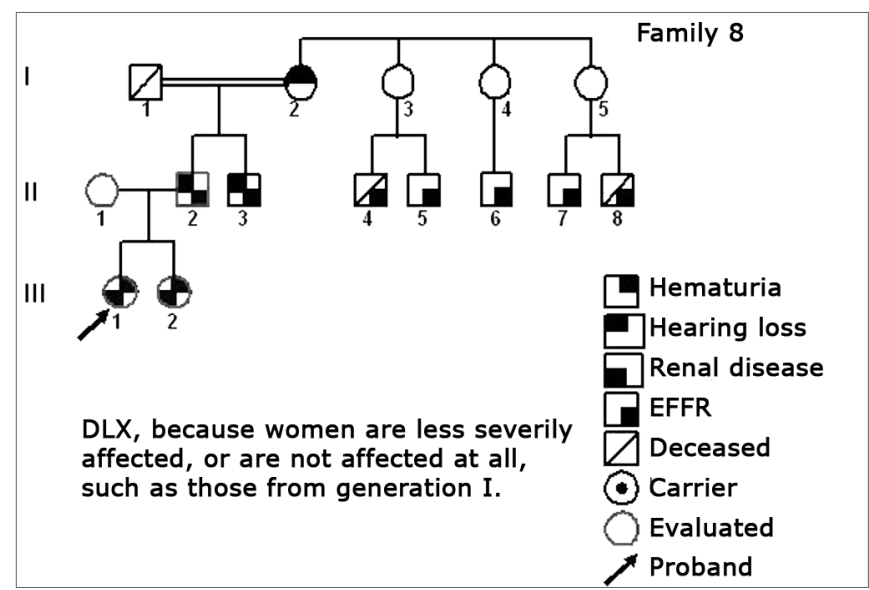

Figure 9. Family 8 Inheritance pattern - DLX, because women are less affected. All the daughters are less severely affect. All the daughters (III-1 and III-2) of the affected men (II-2) are affected, DLX characteristic.

in children and in women or, still, risky in cases of severe renal involvement.

In this sample we found $46.4 \%$ of DLX and $53.6 \%$ DA (Table 4). The intense participation of individuals (9/28) from family 1 may have contributed to this result. According to the literature, the most commonly pattern found was DLX and the analysis of inheritance patterns suggest an autosomal dominant type of AS.1 In approximately $85 \%$ of the inheritance patterns the disease is Xlinked and the mutations were identified in the COL4A5 gene. 2 The classification of the six AS subtypes ${ }^{9}$ is made up by the DA and DLX inheritance patterns. Patients with autosomal dominant As have large clinical variability and an enhanced molecular diagnosis can stress that this type is not so rare. ${ }^{3}$

We analyzed family members without clinical involvement and compared them to those who had renal alteration (Table 6). All of those who presented hearing 
Table 4. Individuals broken down by inheritance pattern.

\begin{tabular}{cccc}
\hline $\begin{array}{c}\text { Inheritance } \\
\text { pattern }\end{array}$ & Frequency & Percentage & \% Cumulative \\
\hline AD & 15 & $53.6 \%$ & $53.6 \%$ \\
DLX & 13 & $46.4 \%$ & $100.0 \%$ \\
\hline Total & 28 & $100.0 \%$ & $100.0 \%$ \\
\hline
\end{tabular}

Table 5. Individuals broken down in relation to their level of hearing loss. (Classification from PARVING \& NEWTON,1995)

\begin{tabular}{cccc}
\hline Hearing loss level & Frequency & Percentage & $\%$ Cumulative \\
\hline $\begin{array}{c}\text { Normal } \\
\text { Mild (21 to } 40 \mathrm{~dB}\end{array}$ & 14 & $53.9 \%$ & $53.9 \%$ \\
$\begin{array}{c}\text { HL) } \\
\begin{array}{c}\text { Moderate }(41 \text { to } \\
60 \mathrm{~dB} \mathrm{HL})\end{array}\end{array}$ & 3 & $11.5 \%$ & $65.4 \%$ \\
\hline Total & 26 & $34.6 \%$ & $100.0 \%$ \\
\hline
\end{tabular}

$48 \%(12 / 25)$ of the patients in any stage of the renal disease had mild to moderate hearing disorder. 52\% (13/25) of the patients at any stage of the renal disease did not have alterations in their audiometric tests.

Hearing alteration happens before the stage of renal failure, showing that it is not determined by uremia. It happens because of alterations in the basal membranes in the organs potentially affected by AS, according to the literature. ${ }^{10-13}$

$\mathrm{HL}$ is never seen without kidney symptoms. ${ }^{12}$

Hearing disorder progression suggests poor renal diagnosis, thus stressing the close tie between hearing alterations and renal failure in men and women. ${ }^{13,14}$

Among the patients assessed in this sample, twelve had hearing disorders in their audiometric test: $11.5 \%$ (3/26) had mild disorder and 34.6\% (9/26) had moderate hearing disorder (Table 5). As far as the age range of patients with mild hearing disorder (3/26) is concerned: one was of school age (11 years) and two were adults. Among the patients with moderate disorder (9/26) the

Table 6. Individual breakdown as to renal involvement and hearing alteration.

\begin{tabular}{lccc}
\hline & Renal Involvement & & TOTAL \\
Hearing alteration & Without alteration & With alteration & 22 \\
No alteration & 9 & 13 & 100,0 \\
Line \% & 40,9 & 59,1 & 64,7 \\
Column \% & 100,0 & 52,0 & 12 \\
With alteration (Mild and Moderate) & 0 & 12 & 100,0 \\
Line \% & 0,0 & 100,0 & 35,3 \\
Column \% & 0,0 & 48,0 & 34 \\
TOTAL & 9 & 25 & 100,0 \\
Line \% & 26,5 & 73,5 & 100,0 \\
Column \% & 100,0 & 100,0 & 10 \\
\hline
\end{tabular}

Exact Fisher Test $\quad 0,0094834717$

Table 7. Breakdown of the individuals as to the audiometric curve configuration.

\begin{tabular}{lccc}
\hline \multicolumn{1}{c}{ Curve configuration } & Frequency & Percentage & \%Cumulative \\
\hline Normal & 13 & $50.0 \%$ & $50.0 \%$ \\
Flat & 3 & $11.5 \%$ & $61.5 \%$ \\
Sudden drop in high frequencies & 1 & $3.8 \%$ & $65.4 \%$ \\
Mild drop in high frequencies & 8 & $30.8 \%$ & $96.2 \%$ \\
U Type & 1 & $3.8 \%$ & $100.0 \%$ \\
\hline Total & 26 & $100.0 \%$ & $100.0 \%$ \\
\hline
\end{tabular}

alteration also had renal involvement. Among those with normal audiometric tests, 59.1\% had renal involvement. There was an association between renal involvement and hearing disorder $(p=0.009)$ among the patients studied. age distribution is the following: one of school age (eight years), two teenagers (14 and 17 years) and six adults. This moderate involvement may happen because of the higher frequency of adults in this subgroup. HL happened in 
$46.1 \%(12 / 26)$ of the individuals evaluated. It is a frequent extra-renal finding in patients with AS. ${ }^{11}$ Hearing loss has been reported as one of the first symptoms of $\mathrm{AS}^{6,14}$, and it may happen at ten years of age and it can be socially meaningless until the person reaches the second decade of life. ${ }^{12}$ The age of hearing loss can be associated with the type of mutation. ${ }^{2,15-17}$

There was no statistically significant correlation between the hearing disorder and the age of the patients studied (Table 9). Notwithstanding, in the general population we do not see hearing disorders in school-aged children, in adolescents and in adults, as noted in our findings. The $\mathrm{chi}^{2}$ test is vulnerable and the sample size added to the numerous possibilities analyzed can explain the fact that there was no association between the hearing disorder and age.

Still in this study group, $50.0 \%(13 / 26)$ of the patients had normal audiometric curves and 30.8\% (8/26) had a mild descending curve in the high frequencies (Table 7).

Table 8. Breakdown of the individuals in relation to hearing loss symmetry.

\begin{tabular}{lccc}
\hline $\begin{array}{c}\text { Comparing } \\
\text { the ears }\end{array}$ & Frequency & Percentage & \% Cumulative \\
\hline Normal & 13 & $50.0 \%$ & $50.0 \%$ \\
Symmetric & 8 & $30.8 \%$ & $80.8 \%$ \\
Asymmetric & 5 & $19.2 \%$ & $100.0 \%$ \\
\hline Total & 26 & $100.0 \%$ & $100.0 \%$ \\
\hline
\end{tabular}

$11.5 \%(3 / 26)$ of the patients had a flat curve. The less frequent curve types were: sudden drop in high frequencies (3.8\%) and $\mathrm{U}$ type (3.8\%).

Three audiometric curve types were seen in the 51 ears with hearing loss: cup shape (47.1\%), descending (41.2\%) and flat (11.7\%). ${ }^{18}$

In the group assessed, we noticed 30.8\% (8/26) of symmetrical losses and $19.2 \%$ had asymmetrical hearing loss $(5 / 26)$ when comparing the two ears (Table 8$)$. The literature reports that the hearing losses are symmetrical. ${ }^{6,10,1} 1$ This sample is small and does not allow us to establish a comparison of both ears.

In this study we noticed $60.0 \%(6 / 10)$ of men with hearing alterations and $37.5 \%(6 / 16)$ of women. $62.5 \%$ $(10 / 16)$ of women without hearing loss and $40.0 \%(4 / 10)$ of men in the same situation (Table 10). Literature reports that hearing loss happens more frequently in men than in women $^{15}$; however, we did not observe any correlation between the hearing disorder and gender in this group studied.

Prognosis has changed with the development of renal transplant, increasing the longevity of patients with AS and renal failure. Making HL development investigation and its rehabilitation relevant for the life quality of these individuals. There is a broad research field to be developed, with genetically modified animals or animal models, in order to understand the disease mechanisms involved in the hearing disorder and normal hearing. These same models can be employed in the study of new treatment modalities.

Table 9. Age range distribution as far as audiometric alterations are concerned.

\begin{tabular}{|c|c|c|c|c|}
\hline \multicolumn{5}{|c|}{ Hearing loss severity } \\
\hline Age ranges & Normal & Mild & Moderate & TOTAL \\
\hline Pre-school & 4 & 0 & 0 & 4 \\
\hline Line \% & 100,0 & 0,0 & 0,0 & 100,0 \\
\hline Column \% & 28,6 & 0,0 & 0,0 & 15,4 \\
\hline School & 2 & 1 & 1 & 4 \\
\hline Line \% & 50,0 & 25,0 & 25,0 & 100,0 \\
\hline Column \% & 14,3 & 33,3 & 11,1 & 15,4 \\
\hline Adolescent & 4 & 0 & 2 & 6 \\
\hline Line \% & 66,7 & 0,0 & 33,3 & 100,0 \\
\hline Column \% & 28,6 & 0,0 & 22,2 & 23,1 \\
\hline Adult & 4 & 2 & 6 & 12 \\
\hline Line \% & 33,3 & 16,7 & 50,0 & 100,0 \\
\hline Column \% & 28,6 & 66,7 & 66,7 & 46,2 \\
\hline TOTAL & 14 & 3 & 9 & 26 \\
\hline Line \% & 53,8 & 11,5 & 34,6 & 100,0 \\
\hline Column \% & 100,0 & 100,0 & 100,0 & 100,0 \\
\hline
\end{tabular}


Table 10. Hearing loss severity distribution as far as gender is concerned.

\begin{tabular}{|c|c|c|c|c|}
\hline \multicolumn{5}{|c|}{ Hearing loss severity } \\
\hline GENDER & Normal & Mild & Moderate & TOTAL \\
\hline Males & 4 & 1 & 5 & 10 \\
\hline Column \% & 28,6 & 33,3 & 55,6 & 38,5 \\
\hline Females & 10 & 2 & 4 & 16 \\
\hline Column \% & 71,4 & 66,7 & 44,4 & 61,5 \\
\hline TOTAL & 14 & 3 & 9 & 26 \\
\hline Line \% & 53,8 & 11,5 & 34,6 & 100,0 \\
\hline Column \% & 100,0 & 100,0 & 100,0 & 100,0 \\
\hline
\end{tabular}

Not only the pathophysiological mechanisms of SNHL in AS still require additional studies, but also the clinical symptoms, hearing alterations and genotype-phenotype relation. The work of multidisciplinary groups from multiple centers shall bring about more information about the disease and its clinical course, diagnostic methods and treatment modalities. HL in AS is still a very exciting area for research by geneticists and otolaryngologists.

\section{CONCLUSIONS}

- The inheritance patterns observed were AD and DLX. The distribution of inheritance patterns, in the present investigation, does not coincide with what is described in the literature.

- Hearing loss is frequently found in AS.

- All of those with hearing alterations also had renal involvement. There is a clear association between renal involvement and hearing alteration $(\mathrm{p}=0.009)$.

- Audiometric curve types more commonly found in this sample were: mild drop in high frequencies and flat curves. The less frequently found curve types were: sudden drop and U-shaped type.

- There was no association between hearing alteration and age, found in the present study.

- We did not find correlations between these hearing alteration and gender in this study.

\section{REFERENCES}

1. Kashtan CE, Michael AF. Alport syndrome. Kidney Int 1996;50:144563.

2. Pirson Y. Making the diagnosis of Alport's syndrome. Kidney Int 1999;56:760-75.
3. Pescucci C, Mari F, Longo I, Vogiatzi P, Caselli R, Scala E, et al Autosomal-dominant Alport syndrome: natural history of a disease due to COL4A3 or COL4A4 gene. Kidney Int 2004;65: 1598-603.

4. Barker DF, Hostikka SL, Zhou J, Chow LT, Oliphant AR, Gerken SC, et al. Identification of mutations in the COL4A5 collagen gene in Alport syndrome. Science 1990;248:1224-7.

5. Kalluri R. Basement membranes: structure, assembly and role in tumour angiogenesis. Nat Rev Cancer 2003:3:422-33.

6. Flinter FA, Cameron JS, Chantler C, Houston I, Bobrow M. Genetics of classic Alport's syndrome. Lancet 1988;1005-7.

7. Parving A, Newton V. Guidelines for description of inherited hearing loss. J Audiol Med 1995;4:2-5.

8. Liu X, Xu L. Nonsyndromic hearing loss: an analysis of audiograms. Ann Otol Rhinol Laryngol 1994;103:428-33.

9. Atkin CL, Hasstedt SJ, Menlove L, Cannon L, Kirschner N, Schwartz $\mathrm{C}$, et al. Mapping of Alport syndrome to the long arm of the X chromosome. Am J Hum Genet 1988;42:249-55.

10. Atkin CL, Gregory MC, Border WA. Alport syndrome. In: Schrier RW, Gottschalk CW. Diseases of the kidney. 4th ed. Boston: Little, Brown 1988. p. 617-41.

11. Perkoff GT, Stephens FE, Dolowitz DA, Tyler FH. A clinical study of hereditary intersticial pyelonephritis. Arch Intern Med 1951;88:191200.

12. Cassady G, Brown K, Cohen M, DeMaria W. Hereditary renal dysfunction and deafness. Pediatrics 1965;35:967-79.

13. Gluber M, Levy M, Broyer M, Naizot C, Gonzales G, Perrin D, et al. Alport's syndrome: a report of 58 cases and a review of the literature. Am J Med1981;70:493-505.

14. Di Paolo B, Vocino V, Bonomini M, Mouawad J, Albertazzi A. Significance of brain stem auditory evoked responses in Alport's syndrome. Contrib Nephrol 1990;80:88-94.

15. Wester DC, Atkin CL, Gregory MC. Alport syndrome: clinical update. J Am Acad Audiol 1995;6:73-9.

16. Barker DF, Pruchno CJ, Jiang X, Atkin CL, Stone EM, Denison JC, et al. A mutation causing Alport syndrome with tardive hearing loss is common in the Western United States. Am J Hum Genet 1996;58:115765.

17. Gross O, Netzer K-O, Lambrecht R, Seibold S, Weber M. Meta-analysis of genotype-phenotype correlation in X- linked Alport syndrome: impact on clinical counselling. Nephrol Dial Transplant 2002;17:121827.

18. Rintelmann FW. Auditory manifestations of Alport's disease syndrome. Trans Am Acad Ophthalmol Otolaryngol 1976;82:375-87. 